\title{
A heterotrophic nanoflagellate grazing on the toxic Cyanobacterium Microcystis aeruginosa
}

\author{
Cui Yan, Jian-Hong Li*, Ju-Jiao Li, Jin Wang and Yong-Ping Weng \\ Jiangsu Key Laboratory of Biodiversity and Biotechnology, Life Sciences College, Nanjing Normal University, Nanjing 210046, \\ P. R. China
}

Received 9 October 2008; Accepted 18 December 2008

\begin{abstract}
Cyanobacterial blooms cause extensive ecological damages in aquatic environments. Heterotrophic nanoflagellates (HNF) play an important role in controlling the populations of cyanobacteria in natural water bodies. In this study, we report a HNF, NF-WJ05, which grazes efficiently on the toxic cyanobacterium Microcystis aeruginosa strain PCC 7806. The morphological characteristics of the nanoflagellate observed by optical microscope and confocal microscope showed that NF-WJ05 could be a Paraphysomonas. The sequences of the internal transcribed spacer (ITS) regions of rDNA including the 5.8S rDNA region was determined and compared with sequences available in databases. The 5.8S rDNA sequence showed a high degree of similarity to those belonging to species of Chromophyta. However, sequences similar to that of its ITS were not found in the databases. Several environmental factors affecting the grazing efficiency of NF-WJ05 on cyanobacteria were evaluated. The more suitable conditions for grazing were $30^{\circ} \mathrm{C}$ and $\mathrm{pH} 5.0$ with stirring. Ammonia inhibited the grazing, whereas low concentrations of phenol increased the grazing rate with an optimal concentration at $50 \mu \mathrm{g} . \mathrm{L}^{-1}$.
\end{abstract}

Key words: Cyanobacteria / grazer / ITS sequence / Microcystis aeruginosa / nanoflagellate

\section{Introduction}

Cyanobacteria are widespread in various ecological niches. They are dominant components in both fresh and marine water bodies. In some cases, cyanobacteria proliferate massively and form a dense layer at the surface of the water bodies, known as bloom, a worldwide phenomenon. Cyanobacterial blooms cause severe damages of aquatic ecosystems and have strong negative impact on the biodiversity (Paerl et al., 2001). In addition, many bloom-forming cyanobacteria are capable of producing toxins including lipopolysaccharide endotoxins, alkaloids, or polyketides (Hallegreff, 1993; Yoo et al., 1995). The most commonly found cyanobacterial toxins are microcystins and their related compounds which are potent hepatotoxins acting on protein phosphatases 1 and $2 \mathrm{~A}$ (Honkanen et al., 1990). The World Health Organization has given guidelines about the maximal levels of cyanotoxins in drinking and entertainment water (Chorus and Bartram, 1999). Microcystis aeruginosa is one of the most common producers of microcystins (Sivonen and Jones,

\footnotetext{
* Corresponding author: lijianhong@njnu.edu.cn
}

1999; Hitzfeld et al., 2000); it is often a dominant species in fresh water blooms. Consequently, Microcystis bloom is one of the most noticeable and the best studied cyanobacterial bloom (Dokulil and Teubner, 1998). The mechanism underlying cyanobacterial bloom formation is still poorly understood. Various factors such as high degree of eutrophication, high temperature, etc., are believed to contribute to the emergence of a cyanobacterial bloom, mostly in spring and summer seasons. A dense cyanobacterial bloom could also disappear in a relatively short time, for which the reason still remains a puzzle. Besides changes in nutrient levels and temperature, biological factors such as the presence of cyanophages or predators of cyanobacteria may contribute to the seasonal changes in cyanobacterial bloom development. Despite a lot of efforts already made, there is still no effective way to eliminate cyanobacterial bloom and control the threat of cyanotoxins.

Within aquatic ecosystems, protozoan predators of cyanobacteria play an important role in the control of cyanobacterial population (Dolan and Simek, 1999; Christaki et al., 2005). Flagellates together with ciliates are considered as key elements in microbial food web including both prokaryotic and eukaryotic organisms 
(Sherr and Sherr, 1994; Vardi et al., 2002). Grazing by flagellates has been reported to contribute to the decline of Microcystis blooms (Nishibe et al., 2002). Biological control of cyanobacterial blooms using microorganisms or protozoa seemed a feasible way (Sigee et al., 1999). Cole and Wynne first reported a flagellate grazer of M. aeruginosa, Ochromonas danica, in 1974 (Cole and Wynne, 1974). Since then, three other Microcystis-grazing flagellates were reported; they were Monas guttula (Sugiura et al., 1992), Collodictyon triciliatum (Klaveness, 1995) and Poterioochromonas malhamensis (Zhang et al., 1996). Ochromonas danica and $P$. malhamensis are mixotrophic nanoflagellate $(2-20 \mu \mathrm{m})$, whereas $C$. triciliatum and M. guttula are hetrotrophic microflagelate $(>20 \mu \mathrm{m})$. Heterotrophic naoflagellates (HNF) are particularly important in microbial food web and their ecological role is well documented (Mariottini and Pane, 2003). They can graze up to $90 \%$ of the total picoplanktonic population $(<2 \mu \mathrm{m})$, including viruses, picophytoplankton, bacteria and cyanobacteria, and hetrotrophic protists (Pernthaler et al., 1996). HNF graze on picocyanobacteria at even a higher rate than ciliates do (Callieri et al., 2002). Grazing by Bodo on a cyanobacterium Synechococcus sp. was investigated in detail and was found to contribute to the consumption of autotrophic planktons in a Mediterrenean bay (Dolan and Simek, 1998). Grazing on Microcystis by heterotrophic nanoflagellates has not yet been reported.

In this study, we report the isolation of a heterotrophic nanoflagellate from water samples of a pond with regular formation of cyanobacterial blooms, and we show that this nanoflagellate can graze on Microcystis rapidly by endocytosis. We made a preliminary identification of the species and investigated the effects of several environmental factors affecting the grazing rate.

\section{Materials and methods}

\section{Isolation of flagellate grazing on Microcystis}

M. aeruginosa PCC 7806 was cultured in the BG11 medium (Rippka et al., 1979). The cultures were exposed to continuous light illumination at $15 \mu \mathrm{mol} \cdot \mathrm{m}^{-2} \cdot \mathrm{s}^{-1}$ fluorescence light at $25{ }^{\circ} \mathrm{C}$. Water samples were taken from bloom-forming ponds and mixed with M. aeruginosa cultures in tubes for two days at room temperature. The tube containing grazer became clearer because the population of $M$. aeruginosa was being eliminated. The grazing nanoflagellate was isolated under a microscope using a fine glass pipe, and incubated in fresh BG11 medium at room temperature; cells of $M$. aeruginosa concentrated by centrifugation was added to flagellate culture as food every day.

\section{Microscopic observation}

To observe the characteristics of the nanoflagellate, Lugol's iodine solution diluted by 10 folds with BG11 medium was added to cells of flagellates to stop their swimming. The course of grazing on $M$. aeruginosa was observed under an optical microscope (Olympus DH-2) and a confocal microscope (MRC-1024, Bio-Red, USA). For observation under an electron microscope, fresh flagellate cells were dropped directly on a copper net, dried naturally, and evaporating the rest moisture in vacuum.

\section{Estimation of grazing rate and effects of environmental factors}

Changes of Microcystis cell densities during incubations with or without the nanoflagellate were monitored in order to estimate the relative grazing rate. The cell densities of Microcystis in the mixture were measured using spectroscopy by following the optical densities at $650 \mathrm{~nm}$. Because the nanoflagellate was colorless and transparent, its absorption of light was negligible. Except the effects of different temperatures on grazing, all other tests were done at $25^{\circ} \mathrm{C}$. The cell density of the grazer used in these tests was about $5 \times 10^{5}$ cell. $\mathrm{mL}^{-1}$; that of Microcystis was about $10 \times 10^{5}$ cell. $\mathrm{mL}^{-1}$.

The culture was exposed to continuous fluorescent light of $15 \mu \mathrm{mol} . \mathrm{m}^{-2} . \mathrm{s}^{-1}$, or kept in a black box when tested in the dark. Filtered air was bubbled into $50 \mathrm{~mL}$ liquid culture in a $250 \mathrm{~mL}$ flask at about $3.0 \mathrm{~L} \cdot \mathrm{min}^{-1}$. A gentle stirring was produced by a magnetic agitator at $200 \mathrm{rpm}$. Different $\mathrm{pH}$ was adjusted by $0.5 \mathrm{M} \mathrm{NaOH}$ or $0.5 \mathrm{M} \mathrm{HCl}$.

To investigate the effects of ammonia on the grazing, different volumes of a $\mathrm{NH}_{4} \mathrm{Cl}$ solution at $500 \mathrm{mg} . \mathrm{L}^{-1}$ were added into $50 \mathrm{~mL}$ aliquots of the mixtures of the grazer and Microcystis at a final concentration of 27, 5.4 and $1.08 \mathrm{mg} . \mathrm{L}^{-1}$, respectively. Ammonia concentration was determined using Nessler's reagent and a spectrophotometer.

To investigate the effect of phenol on grazing, phenol was added into $50 \mathrm{~mL}$ aliquots of the mixture of grazer and Microcystis at the final concentration of 10, 30, 50, 70 and $90 \mu \mathrm{g} . \mathrm{L}^{-1}$, respectively.

\section{DNA sequencing}

A culture of fresh flagellates was centrifuged, and cell pellet was resuspended in a buffer containing $10 \mathrm{mM}$ TrisEDTA. Total DNA of the flagellate was extracted as reported (Boenigk et al., 2005). For PCR, the forward primer (5'-GGAAGTAAAAGTCGTAACAAGG-3') and the reverse primer (5'-TCCTCCGCTTATTGATATGC-3') were used to amplify the ITS-5.8S rDNA sequence of the flagellate. The annealing temperature was $55{ }^{\circ} \mathrm{C}$, and 35 cycles were applied. PCR product was sequenced by Shanghai Biotech Company, China.

\section{Phylogenetic analysis}

Analysis of DNA sequences was done at the NCBI website (www.ncbi.nlm.nih.gov). Eleven 5.8S rRNA 

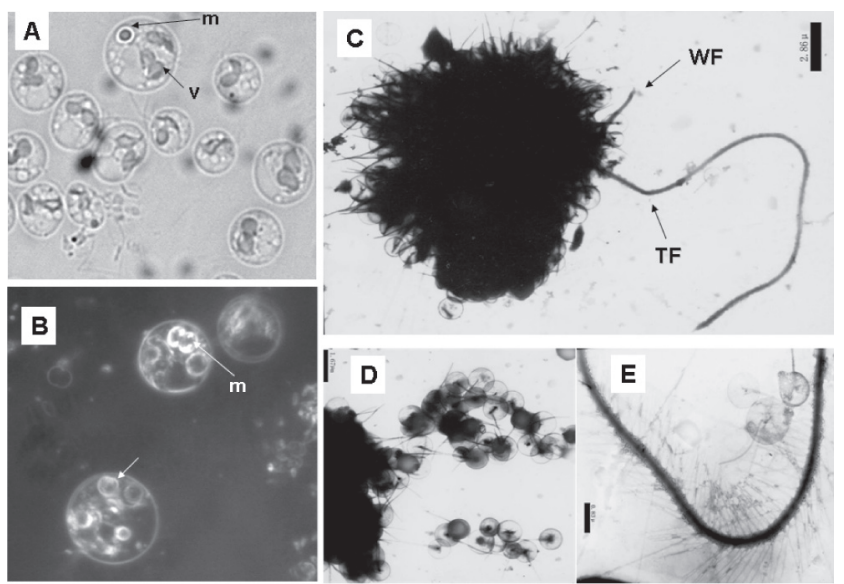

Fig. 1. Nanoflagellate observation under a light microscope (A and B) or an electron microscope (C-E). A, bright-field picture evidentiating the food vacuoles after Microcystis cells were digested; m, Microcystis cell; v, vacuoles. B, dark-field picture. C, a whole cell. D, clypeate squamae. E, tinsel flagellum. WF, whiplash type flagellum; TF, tinsel-type flagellum.

sequences most similar to the newly identified sequence in this study were selected to build an unrooted phylogenic tree. Sequence alignment and tree construction were performed with MEGA3.1 and Neighbor-joining method (Kumar et al., 2004).

\section{Results}

\section{Characterization and classification of Microcystis-grazing nanoflagellate}

A Microcystis-grazing nanoflagellate NF-WJ05 was isolated, which was colorless, motile and spherical or ovoid. The ellipsoidal cell body was about 3.5 to $6.0 \mu \mathrm{m}$ in width, and 6.0 to $7.5 \mu \mathrm{m}$ in length. Chloroplasts and stigma were absent. Two food vacuoles were seen after $M$. aeruginosa cells were digested. Normally bearing a single flagellum, two to four flagella appeared at different stages of the life cycle. Swimming speed in liquid was about $5 \mu \mathrm{m} . \mathrm{s}^{-1}$. Cells which were ingesting $M$. aeruginosa moved slower. Doubling time of the flagellate growth was 1 to 1.4 day (data not show).

To study the characteristics of the nanoflagellate in more details, we used transmission electron microscope to investigate its structure and morphology. The cells were too fragile to be fixed by normal chemical fixers such as glutaraldehyde, formaldehyde or methanol. These chemicals caused the nanoflagellate to collapse immediately when added. So we dropped fresh cells on a copper net and dried them naturally for observation. Pictures obtained under the electron microscopy showed that the flagellate was coated with clypeate squamae. It had two unequal flagella, a long hairy flagellum (tinseltype) and a short smooth flagellum (whiplash type) (Fig. 1). From the morphological and physical properties,

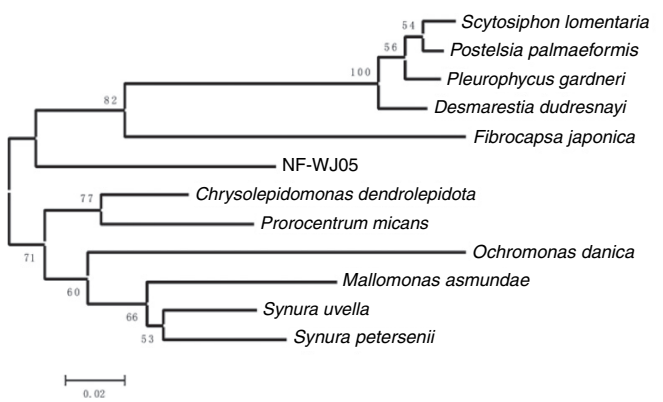

Phaeophyceae Phaeophyceae Phaeophyceae Phaeophyceae Raphidophyceae Chrysophyceae Dinophyceae Chrysophyceae Chrysophyceae Chrysophyceae Chrysophyceae

Fig. 2. Phylogenetic tree of NF-WJ05 and related taxa, obtained by neighbor-joining analysis of the 5.8S rRNA genes. Bootstrap analysis was performed with 3000 resampling replicates and the bootstrap values are given at each node. The GenBank accession numbers of the sequences here presented should also be displayed in the figure.

this flagellate could belong to Paraphysomonas, Chrysophyceae.

The analysis of the rDNA sequence is an essential tool to verify the genetic background of an organism (Redecker et al., 1999; Goodwin et al., 2001). We analyzed the ITS sequence of the flagellate rDNA. A DNA fragment of 756 bp was amplified, which included the ITS1 sequence, the 5.8S rDNA sequence and the ITS2 sequences (GenBank accession no. DQ223654). The results of the sequence comparison showed that the 5.8S rDNA sequence of NF-WJ05 had a high similarity to those from species of Chrysophyceae, Phaeophyceae, Raphidophyceae, Dinophyceae, and Chromophyta. The most related sequence is that from the species Chrysolepidomonas dendrolepidota (Fig. 2). While C. dendrolepidota has a single chloroplast, and an eyespot, these features are not observed for NF-WJ05. Consistent with these observations, NF-WJ05 could grow only under heterotrophic conditions. The ITS sequence of NF-WJ05 did not show sequence similarity to any sequences in databases.

\section{Grazing on Microcystis and food selectivity}

NF-WJ05 grazed $M$. aeruginosa cells through endocytosis (Fig. 3). The course of grazing was very fast, taken about $3 \mathrm{~s}$ to engulf one cell. More than ten $M$. aeruginosa cells could be seen in one flagellate when starved flagellates were fed with $M$. aeruginosa cells. No toxic effect to the grazer was observed in continuous feeding. NF-WJ05 is resistant to the toxin produced by the Microcystis; the toxin in the mixture was not degraded (data not show) although cells of Microcystis were digested. For those flagellates which were continuously fed, the average grazing rate was about $1-4$ cells of $M$. aeruginosa for each flagellate per day.

\section{Effects of environmental factors on grazing rates}

The effects of some environmental factors on the grazing rate were investigated. The physical and chemical 

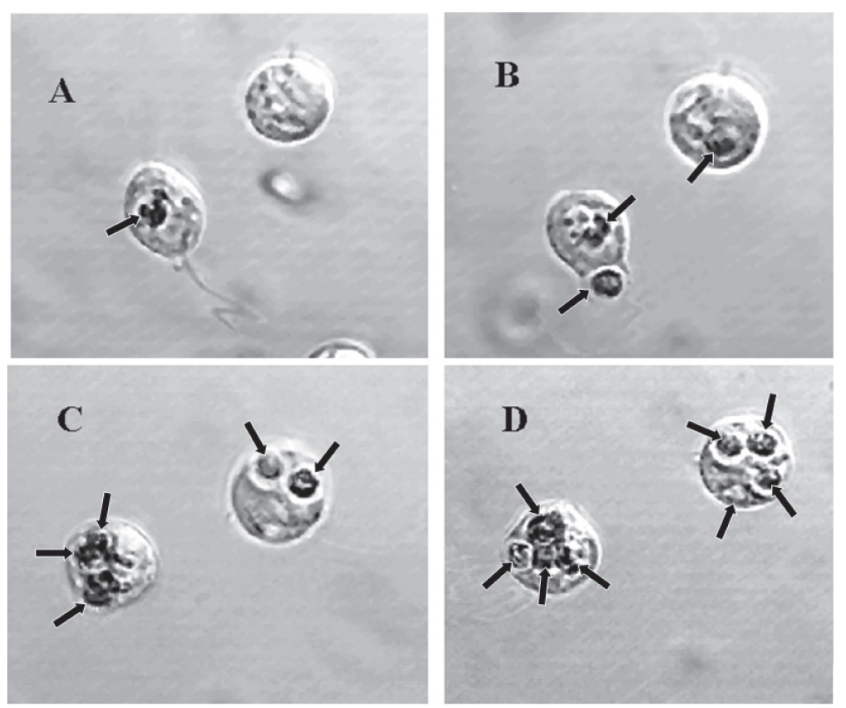

Fig. 3. Time course of grazing on M. aeruginosa by NF-WJ05. Pictures were taken by a confocal scanning microscope at room temperature. Black arrows point to the Microcystis cells. A, two starved nanoflagellates before grazing. B, 1 min after, the same nanoflagellate was grazing on a Microcystis cell by endocytosis. C, 5 min after the grazing was started. D, 10 min after the grazing was started. One nanoflagellate ingested several M. aeruginosa cells.
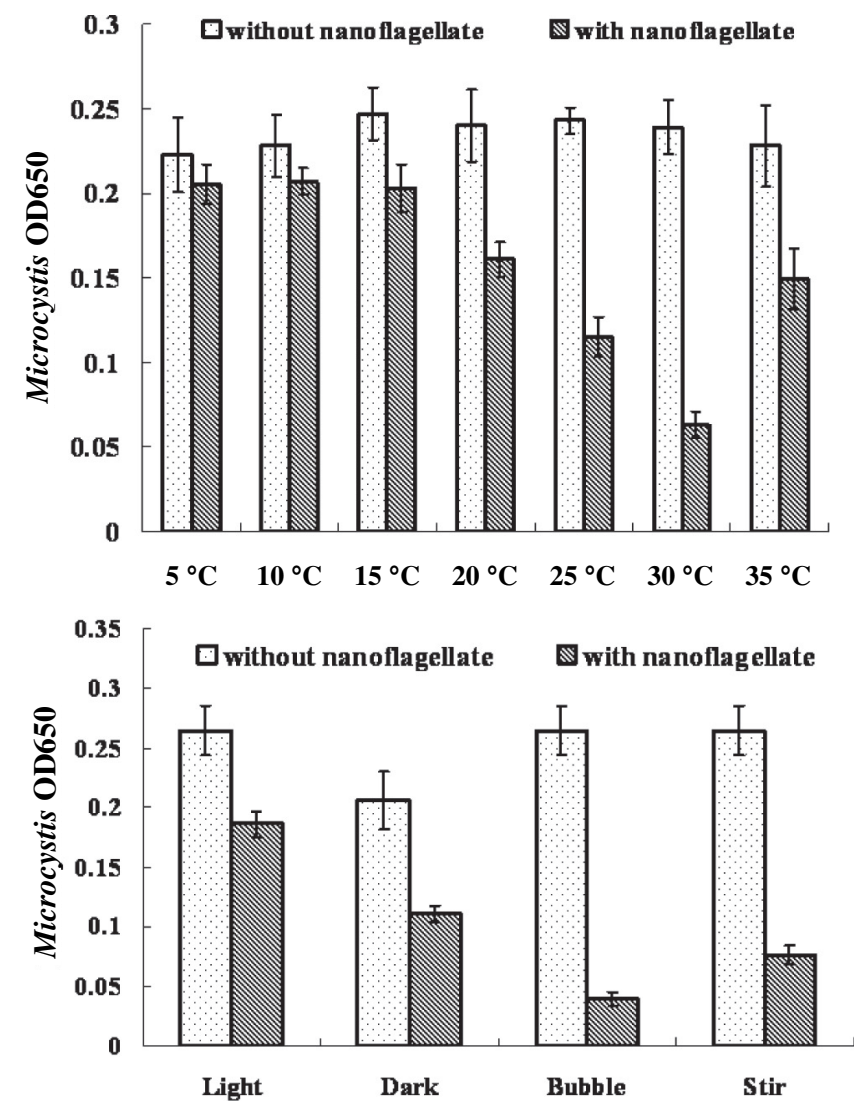

Fig. 4. Effects of some physical environmental factors, illumination, bubbling and stirring, on the elimination of $M$. aeruginosa by NF-WJ05. Each value is means \pm SD of three replicates.
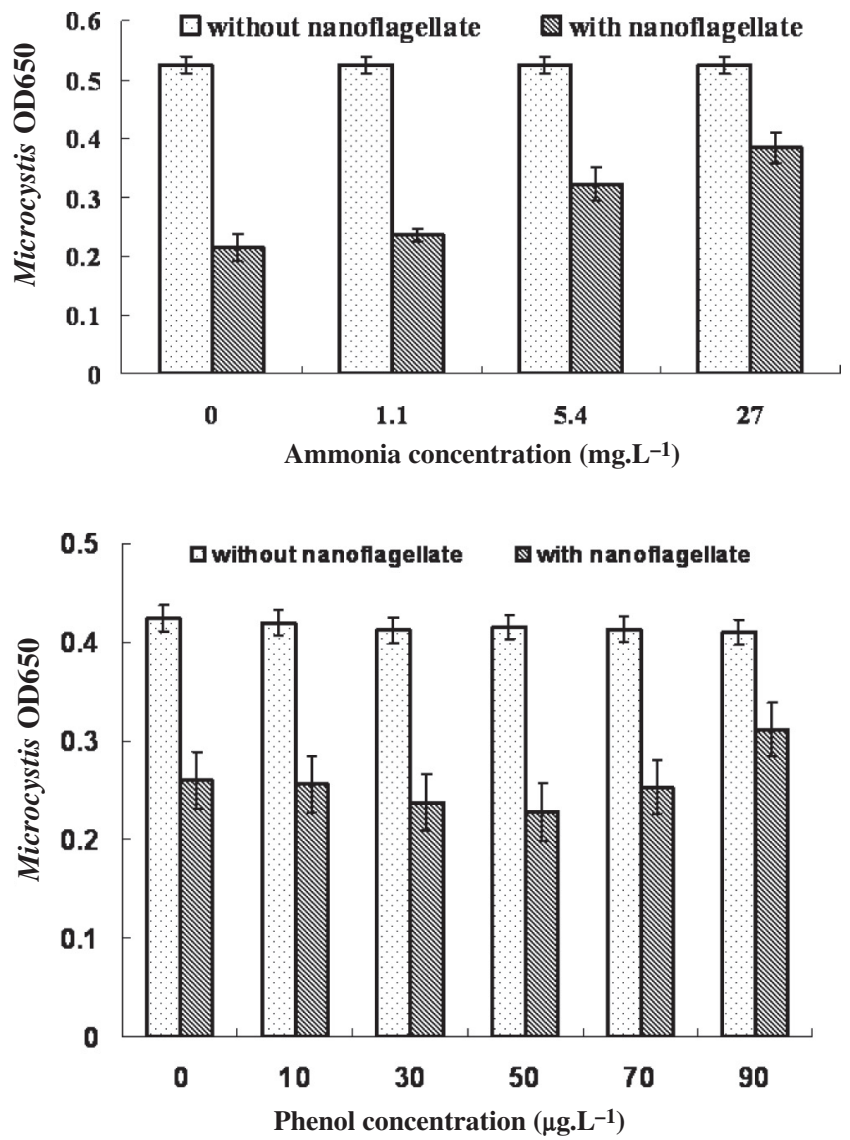

Fig. 5. Effects of ammonia and phenol on the elimination of $M$. aeruginosa by NF-WJ05. Each value is means $\pm \mathrm{SD}$ of three replicates.

factors studied here are some which may be associated with the occurrence of cyanobacterial blooms and subject to changes in natural surface water. The effects of temperature on the grazing rate of $M$. aeruginosa by NF-WJ05 are shown in Figure 4. From 15 to $30{ }^{\circ} \mathrm{C}$, the grazing rate increased with increasing temperature, reaching the optimal at $30{ }^{\circ} \mathrm{C}$. When the temperature reached $35{ }^{\circ} \mathrm{C}$, the grazing rate decreased. At a temperature as low as $5{ }^{\circ} \mathrm{C}$, the nanoflagellate could still graze on M. aeruginosa.

NF-WJ05 preferred a dark environment. The elimination rate of $M$. aeruginosa by NF-WJ05 was about $5 \%$ higher in the dark than in the light within a period of $24 \mathrm{~h}$. Air bubbling into the liquid culture and a gentle stirring were helpful to grazing efficiency (Fig. 4).

Ammonia is a common toxic substance in polluted water bodies. So we tested the effects of different levels of ammonia on the grazing rate of the nanoflagellate. The results showed that the grazing rate was negatively affected by increasing levels of ammonia. When the concentration of ammonia was at $27.0 \mathrm{mg} . \mathrm{L}^{-1}$, the grazing rate of NF-WJ05 decreased by $45.3 \%$ as compared to the control (Fig. 5).

Phenol is an organic toxic substance commonly found in water bodies polluted by chemical waste and is toxic 
to aquatic organisms (IPCS, 1994). However, low concentrations of phenol promoted the grazing activity of NF-WJ05. When the concentration of phenol was $50 \mu \mathrm{g} . \mathrm{L}^{-1}$, the grazing rate was $12.5 \%$ higher than that found without phenol, but a concentration of phenol above $70 \mu \mathrm{g} . \mathrm{L}^{-1}$ inhibited the grazing.

\section{Discussion}

Although the contribution of HNFs to the balance of aquatic ecosystems has been noticed, in many cases the grazing effects of heterotrophic nanoflagellates on cyanobacterial population is poorly understood or underestimated. HNFs are tiny in size and colorless, and normal fixing procedures with chemicals may cause them to collapse, which could be one of the reasons for the negligence of these organisms in water samples. In this study, we isolated the heterotrophic nanoflagellate NF-WJ05 and investigated its characteristics and the course of its grazing on Microcystis in detail. Besides grazing Microcysits, NF-WJ05 also ingested another unicellular picocyanobacterium, Synechocystis PCC 6803, but not the filamentous strain Anabaena PCC 7120; it could graze yeast cells, but not the green algae Chlorella ellipsoidae. NF-WJ05 could also grow using milk and yolk as food. Curiously, it did not feed on Escherichia coli. Although protists grazing is size-selective in most cases (Šimek and Chrzanowski, 1992), NF-WJ05 followed apparently more complex rules to select its food.

DNA sequence analysis was an effective method to identify a microorganism. Taking into account that the 18S RNA gene was too conserved to allow a discrimination of different families, we used the ITS sequence as molecular marker to identify the species. However, since few ITS sequences of Chromophyta were available in the database for detailed analysis, more evidence will be required to determine whether $\mathrm{NF}-\mathrm{WJ} 05$ belongs to a new species.

We have also investigated the effects of several environmental factors on the grazing rate of this flagellate on Microcystis. During blooms formation, thousands of $M$. aeruginosa cells aggregate to form a colony which may be too big to be grazed by nanoflagellates. However during winter, cyanobacterial blooms disappear, and some cells of Microcystis survive in the form of single cells during cold seasons (Kong and Gao, 2005). NF-WJ05 could graze $M$. aeruginosa at $5{ }^{\circ} \mathrm{C}$; and survived in the refrigerator at $4{ }^{\circ} \mathrm{C}$ for at least three months (data not show). In this case, such flagellate may contribute to decreasing the population size of Microcystis at the beginning of bloom development, and help to attenuate the formation of large-scale cyanobacterial blooms.

Air bubbling and gentle stirring increased the grazing of NF-WJ05. These effects could be due to the increase in the levels of oxygen, which may help the heterotrophic NF-WJ05 to better digest the food. NF-WJ05 seemed to prefer the environment without light, since the presence of UV illumination inhibited HNFs' grazing (Ochs and
Eddy, 1998). NF-WJ05 preferred lower pH; when the $\mathrm{pH}$ value increased from 5.0 to 8.0, the grazing rate decreased by $17 \%$ (data not shown). High concentrations of ammonia are toxic to aquatic organisms (Randall and Tsui, 2002). A same effect to HNF-WJ05 was observed in this study.

There are many natural enemies against cyanobacteria in a hydro-ecosystem, which include virus, bacteria, protozoa, etc. The interaction among these populations allows them to stay in balance as communities under normal conditions. Our observation should be helpful to reveal the relationship between Microcystis population and nanoflagellates in natural environment. Increasing the grazer communities could be considered as a means to control toxic Microcystis blooms. All our tests were done under laboratory conditions. How to maintain a high amount of grazers in a bloom-forming water body under natural environment would be an interesting issue to investigate. Further studies will be required to evaluate the application of NF-WJ05 for the treatment of cyanobacterial blooms in a natural water body.

Acknowledgements. We thank Professor Cheng-Cai Zhang for making constructive commentaries on the manuscript. We thank anonymous two reviewers for their kind comments on the manuscript. The project was sponsored by the Scientific Research Foundation for the Returned Overseas Chinese Scholars, State Education Ministry.

\section{References}

Boenigk J., Pfandl K., Stadler P. and Chatzinotas A., 2005. High diversity of the 'Spumella-like' flagellates: an investigation based on the SSU rRNA gene sequences of isolates from habitats located in six different geographic regions. Environ. Microbiol., 7, 685-697.

Callieri C., Karjalainen S.M. and Passoni S., 2002. Grazing by ciliates and heterotrophic nanoflagellates on picocyanobacteria in Lago Maggiore, Italy. J. Plankton Res., 24, 785796.

Chorus I. and Bartram J., 1999. Toxic cyanobacteria in water: A guide to their public health consequences, monitoring and management, Published on Behalf of WHO. F and FN Spon.

Christaki U., Vazquez-Dominguez E., Courties C. and Lebaron P., 2005. Grazing impact of different heterotrophic nanoflagellates on eukaryotic (Ostreococcus tauri) and prokaryotic picoautotrophs (Prochlorococcus and Synechococcus). Environ. Microbiol., 7, 1200-1210.

Cole G.T. and Wynne M.J., 1974. Endocytosis of Microcystis aeruginosa by Ochromonas danica. J. Phycol., 10, 397-410.

Dokulil M.T. and Teubner K., 1998. Cyanobacterial dominance in eutrophic lakes: Causes-Consequences-Solutions. J. Lake Sci., 10, 357-370.

Dolan J.R. and Šimek K., 1998. Ingestion and digestion of an autotrophic picoplankter, Synechococcous, by a heterotrophic nanoflagellate, Bodo saltans. Limnol. Oceanogr., 43, 1740-1746. 
Dolan J.R. and Šimek K., 1999. Diel periodicity in Synechococcus populations and grazing by heterotrophic nanoflagellates: Analysis of food vacuole contents. Limnol. Oceanogr., 44, 1565-1570.

Goodwin S.B., Dunkle L.D. and Zismann V.L., 2001. Phylogenetic analysis of Cercospora and Mycosphaerella based on the internal transcribed spacer region of ribosomal DNA. Phytopathology, 91, 648-658.

Hallegreff G.M., 1993. A review of harmful algal bloom and their apparent global increase. Phycologia, 32, 79-99.

Hitzfeld B.C., Hoger S.J. and Dietrich D.R., 2000. Cyanobacterial toxins: Removal during drinking water treatment and human risk assessment. Environ. Health Perspect, 108, Suppl. 1, 113-122.

Honkanen R.E., Zwiller J., Mooren R.E., Daily S.L., Khatrall B.S., Dukelow M. and Boynton A.L., 1990. Characterization of microcystin-LR, a potent inhibitor of type 1 and type 2A protein phosphatases. J. Biol. Chem., 265, 1940119404.

IPCS, 1994. Phenol health and safety guide, health and safety guide $\mathrm{n}^{\circ} 88$, International Programme on Chemical Safety (IPCS), Environmental Health Criteria 161, World Health Organization, Geneva.

Klaveness D., 1995. Collodictyon triciliatum H.J. Carter (1865) a common but fixation-sensitive algivorous flagellate from the limnopelagial. Nordic J. Freshw. Res., 70, 3-11.

Kong F.Q. and Gao G., 2005. Hypothesis on cyanobacteria bloom-forming mechanism in large shallow eutrophic lakes. Acta Ecol. Sinica, 25, 589-595.

Kumar S., Tamura K. and Nei M., 2004. MEGA3: Integrated software for molecular evolutionary genetics analysis and sequence alignment. Brief. Bioinform., 5, 150-163.

Mariottini G.L. and Pane L., 2003. Ecology of planktonic heterotrophic flagellates, a review. Riv. Biol., 96, 55-71.

Nishibe Y., Kawabata Z. and Nakano S., 2002. Grazing on Microcystis aeruginosa by the heterotrophic flagellate Collodictyon triciliatum in a hypertrophic pond. Aquat. Microb. Ecol., 29, 173-179.

Ochs C.A. and Eddy L.P., 1998. Effects of UV-A (320 to 399 nanometers) on grazing pressure of a marine heterotrophic nanoflagellate on strains of the unicellular cyanobacteria Synechococcus spp. Appl. Environ. Microbiol., 64, 287-293.

Paerl H.W., Fulton R.S. III., Moisander P.H. and Dyble J., 2001. Harmful freshwater algal blooms, with an emphasis on cyanobacteria. Sci. World J., 1, 76-113.
Pernthaler J., Šimek K., Sattler B., Schwarzenbacher A., Bobkova J. and Psenner R., 1996. Short-term changes of protozoan control on autotrophic picoplankton in an oligomesotrophic lake. J. Plankton. Res., 18, 443-462.

Randall D.J. and Tsui T.K., 2002. Ammonia toxicity in fish. Mar. Pollut. Bull., 45, 17-23.

Redecker D., Hijri M., Dulieu H. and Sanders I.R., 1999. Phylogenetic analysis of a dataset of fungal 5.8S rDNA sequences shows that highly divergent copies of internal transcribed spacers reported from Scutellospora castanea are of Ascomycete origin. Fungal Genet. Biol., 28, 238-244.

Rippka R., Deruelles J.D., Waterbury J., Herdman M. and Stanier R., 1979. Generic assignments, strain histories and properties of pure cultures of cyanobacteria. J. Gen. Microbiol., 111, 1-61.

Sherr E.B. and Sherr B.F., 1994. Bacterivory and herbivoryKey roles of phagotrophic protests in pelagic food webs. Microbial Ecol., 28, 223-235.

Sigee D.C., Glenn R., Andrews M.J., Bellinger E.G., Butler R.D., Epton H.A.S. and Hendry R.D., 1999. Biological control of cyanobacteria: principles and possibilities. Hydrobiologia, 395/396, 161-172.

Šimek K. and Chrzanowski T.H., 1992. Direct and indirect evidence of size-selective grazing on pelagic bacteria by freshwater nanoflagellates. Appl. Environ. Microbiol., 58, 3715-3720.

Sivonen K. and Jones G., 1999. Cyanobacterial toxins. In: Chorus I., Bartram J. (eds.), Toxic Cyanobacteria in Water, E and FN Spon London, London, UK, 41-111.

Sugiura N., Inamori Y., Ouchiyama T. and Sudo R., 1992. Degradation of cyanobacteria, Microcystis by microflagellate, Monas guttula. Water Sci. Technol., 26, 2173-2176.

Vardi A., Schatz D., Beeri K., Motro U., Sukenik A., Levine A. and Kaplan A., 2002. Dinoflagellate-cyanobacterium communication may determine the composition of phytoplankton assemblage in a mesotrophic lake. Curr. Biol., 12, 1767-1772.

Yoo S., Carmichael W.W., Hoehn R.C. and Hrudey S.E., 1995. Cyanobacterial (Blue-green Algal) toxins: a resource guide, American Water Works Association Research Foundation, Denver, Colorado.

Zhang X., Watanabe M.M. and Inouye I., 1996. Light and electron microscopy of grazing by Poterioochromonas malhamensis (Chrysophyceae) on a range of phytoplankton taxa. J. Phycol., 32, 37-46. 